\title{
OBITUARY
}

\section{DOREEN TREDREA}

3I.06.1898 - 10.05.1986

Doreen Tredrea, born in Kimberley at the end of the last century - trained at the Westminster Hospital, London, came back to work in Kimberley in 1934 after a short spell at Addington Hospital.

She gave loyal service until 1953.07.31 when she retired. Handicapped by failing sight, she ended her days at the Helen Keller Hostel, Pinelands, Cape.

She will be missed by her many colleagues and friends in the Northern Cape. 